\title{
Future Girls of STEM Summer Camp Pilot: Teaching Girls about Engineering and Leadership Through Hands-On Activities and Mentorship
}

\author{
Rebecca R. Essig', Behin Elahi'2, Jennifer L. Hunter ${ }^{3}$, Atefeh Mohammadpour'2, Kimberly W. O'Connor ${ }^{3}$ \\ ${ }^{1}$ Department of Civil and Mechanical Engineering, ${ }^{2}$ School of Polytechnic, and ${ }^{3}$ Department of Organizational Leadership, Purdue University Fort Wayne, \\ Fort Wayne, IN \\ Keywords: Women in STEM, Engineering Outreach, Engineering Summer Camp \\ Publication Date: November 17, 2020
}

DOI: https://doi.org/10.15695/jstem/v3i1.09

\begin{abstract}
Future Girls of STEM" is a university-sponsored, summer camp outreach program that was designed and implemented by an all-female faculty group to increase young girls' interest in pursuing future careers in science, technology, engineering, and mathematics (STEM). This paper discusses the logistics and results of the pilot Future Girls of STEM camp, which was held in the summer of 2019 for seven to twelve-year-old girls. The four-day summer camp featured female engineers from local industry, who shared personal stories of their careers and helped campers work through engineering and leadership activities. Researchers assessed whether completing the activities increased participants' understanding of, interest in, and self-efficacy in engineering topics, majors, and careers. Results showed an increased interest and self-reported understanding of engineering topics after participants completed the camp, as well as high self-efficacy throughout the camp experience. The Future Girls of STEM program, and its hands-on, interactive activities, can be transferred to other locations or universities with varying resources available.
\end{abstract}

\section{INTRODUCTION}

The underrepresentation of women in STEM (science, technology, engineering, and mathematics) majors and careers is of great concern. Though overall enrollment in engineering undergraduate programs steadily increased by $22 \%$ from 2015 through 2018, the overall percentage of women in these programs rose from $19.9 \%$ in 2015 to only $21.3 \%$ in 2018 (Roy, 2018; Yoder, 2015). Even as K-12 schools are trying to make STEM education for girls a priority, studies indicate that a large percentage of girls lose their interest in STEM before and/or during middle school (Choney, 2018). Various explanations for this include possible peer pressure, an absence of role models for girls, or a lack of support from parents and teachers (Choney, 2018; Microsoft.com, n.d.; Roberts and Hughes, 2019). Studies by Sandrin and Borror (2013) and Noel-Levitz (2007) also report that many elementary and middle school female students often do not have a clear vision or understanding of various engineering fields. Among college students, research shows that women who drop out of engineering report lower confidence in en- gineering skills, even though their competence is comparable with students who remain enrolled (Cech et al., 2011). Thus, exposure to and understanding of careers, increases in self-confidence, and the availability of positive mentors and educators are all critical factors for recruiting and retaining women in STEM fields (Gossage, 2011).

Providing quality community engagement and outreach programming is also vital to increasing female representation in STEM (Blandino and Hardin, 2015; Gooden et al., 2010; Hubelbank et al., 2007). For example, Anderson and Gilbride (2003) showed that girls who participated in outreach programming reported increased interest in pursuing engineering as a career. Deckard and Quarfoot (2014) reported that a single-day exposure of young girls to engineering experiences reshaped their understanding of engineering fields. Blandino and Hardin (2015) assessed the short-term impact of an outreach program called "Engineers Week" on middle school students and reported significantly higher interest in engineering after the event. Gooden et al. (2010) and 
McCormick et al. (2014) found that follow-up involvement and repeated outreach highly increased female students' interest in engineering fields in the college.

It is against this backdrop that the Future Girls of STEM (FGS) outreach project was created to encourage elementary school girls' interest, participation, and self-efficacy in STEM. Self-efficacy refers to one's personal judgment about his or her ability to succeed, with prior research showing that those with higher self-efficacy have higher performance levels and longer persistence in STEM fields as compared to those with lower levels of self-efficacy (Backer and Halualani, 2012). FGS's hands-on activities and summer camp structure, as outlined in this paper, are generalizable to fit various programming locations and needs. The research and results presented in this paper occurred during the pilot FGS summer camp where we aimed to answer the following questions:

Does participation in engineering activities led by female engineering mentors impact the participants'

1. interest in engineering?

2. self-reported understanding of engineering disciplines?

3. self-efficacy of participants?

\section{METHODS}

Camp development and implementation were divided into five main steps shown: 1) initial planning and topic selection; 2) selection of community and industry partners; 3 ) design of hands-on activities; 4) camp implementation, and; 5) assessment. Each step is explained in detail in the following subsections.

Initial Planning and Topic Selection. During the initial planning stages, the faculty focused on general logistics of the summer camp, including target age group, what topics should be covered, potential partners to contact, and what data would be collected for assessment. 2nd to $3 \mathrm{rd}$ grade girls (8-10 years old) were selected as the target group because the faculty wanted to teach girls about engineering before they entered grade levels where students choose elective courses and educational paths. With this age group in mind, it was determined that the camp should run for four half-days (4 hours per day) to accommodate participants' energy levels and attention span. Each day of the camp was designed to teach the participants about a different engineering topic, and specific topics were selected to align with the faculty leaders' expertise. Topics selected included: civil engineering, environmental engineering, industrial engineering and robotics, cybersecurity, and leadership. Once the general details were determined, the faculty reached out to the potential community and industry partners.

Journal of STEM Outreach
Community and Industry Partner Selection. Because of the age and gender of the target group, the local chapter of the Girl Scouts of the United States of America (Girl Scouts or GS) was a natural partner for the FGS camp. Recently, the Girl Scouts set a goal of engaging 2.5 million girls in their STEM programs by 2025 in an effort to close the STEM field gender gap (Girl Scouts, 2017). As part of their new program, the Girl Scouts launched 23 new STEM and outdoor badges, and will soon launch 18 cybersecurity badges and a series of space science badges, with the aim of encouraging girls' interest in STEM subjects and environmental conservation. The Girl Scouts' commitment to encouraging girls to discover and excel in STEM fields has yielded real results; Girl Scouts are almost twice as likely as non-Girl Scouts to participate in STEM activities (60 percent versus 35 percent), and 77 percent of girls say that because of Girl Scouts, they are considering a career in technology. Because of the closely aligned goals, this organization was a great community partner for the FGS camp. They provided enormous support by publicizing the camp, managing registrations and fee collection, and communicating directly with parents and families about the camp. This allowed our team to focus on developing dayto-day schedules and activities. When developing FGS camp activities, faculty worked to meet badge requirements so that campers could earn new badges while participating in the camp.

In addition to the Girl Scouts, five female industry partners participated in the camp to provide real-life examples and personal stories of being a woman engineer. They participated and led various activities throughout the week. Industry partners joined the camp from a state department of transportation, automobile manufacturer, city municipality water utility, and information technology services at the university. Each of these industry partners works within their organizations to increase the number of women into engineering and technology careers and understand the importance of investing in girls to change the STEM pipeline and the future of its workforce.

Hands-on Activity Design. FGS activities were designed to explore engineering in a fun and interactive way. It was intended to engage and inspire girls towards confidence and interest in STEM careers. Each day was themed around a specific engineering topic, and leadership concepts were woven throughout. Daily schedules were designed to be educational, interactive, and introduce campers to real-life engineering examples around campus. For example, each day began with a "Brick Building Challenge", which offered an opportunity for girls to build a structure based on the day's theme and then share what they had created. Other camp activities and learning objectives are outlined in the following subsections and summarized in Table 1. All learning objectives were designed to align with Bloom's taxonomy levels of remember, understand, and apply (Krathwohl, 2002). 
Table 1. Summary of activities and interactions in each day of the camp.

\begin{tabular}{|c|c|c|}
\hline Day of Camp & Industry Partner(s) & Activities and Interactions \\
\hline Day 1: Civil Engineering & $\begin{array}{l}\text { Bridge Engineer with State } \\
\text { Department of Transportation }\end{array}$ & $\begin{array}{l}\text { - } \quad \text { Built structures using spaghetti and marshmallows } \\
\text { - } \quad \text { Watched video on bridge design } \\
\text { - } \quad \text { Doured bridge construction site } \\
\text { should be located }\end{array}$ \\
\hline $\begin{array}{l}\text { Day 2: Industrial Engi- } \\
\text { neering and Robotics }\end{array}$ & $\begin{array}{l}\text { Industrial engineers from } \\
\text { international automotive man- } \\
\text { ufacturer }\end{array}$ & $\begin{array}{l}\text { - } \quad \text { Practiced coding basics by programming robotic bees } \\
\text { - } \quad \text { Toured a 3D printing lab } \\
\text { Visited the Virtual Reality (VR) and Robotics Lab and learned about real-life } \\
\text { applications of VR and robots } \\
\text { - Human Bingo game to learn about recognizing and embracing differences be- } \\
\text { tween people }\end{array}$ \\
\hline $\begin{array}{l}\text { Day 3: Environmental } \\
\text { Engineering }\end{array}$ & $\begin{array}{l}\text { Water resources engineer from } \\
\text { city water utility }\end{array}$ & $\begin{array}{l}\text { - Learned how to observe natural water health using sight and smell while over- } \\
\text { looking a local river } \\
\text { Analyzed and compared river and sink water alkalinity, } \mathrm{pH} \text {, hardness, iron, chlo- } \\
\text { rine, copper, nitrate, and nitrite } \\
\text { - Toured a water biology lab }\end{array}$ \\
\hline Day 4: Cybersecurity & $\begin{array}{l}\text { Informational technology } \\
\text { specialist from university }\end{array}$ & $\begin{array}{l}\text { - Tested the strength of personal passwords using online tools to learn the impor- } \\
\text { tance of password protection } \\
\text { Introduced social media and online safety by looking at example accounts. Dis- } \\
\text { cussion centered on encouraging the girls to talk to teachers and parents } \\
\text { - Discussed how to identify and handle cyberbullying } \\
\text { - Reviewed the basics of cybersecurity and learn what information is private and } \\
\text { how to share it safely } \\
\text { Practiced effective teamwork and learned how engineers work in groups to de- } \\
\text { velop better products }\end{array}$ \\
\hline
\end{tabular}

Day 1: Civil Engineering. The first day of camp focused on civil engineering and the industry partner was a civil engineer from the state department of transportation. Because civil engineering (CE) is a broad field, the lead faculty decided to focus activities on structural and construction engineering to make the day more cohesive. Through these activities, campers accomplished the following learning objectives:

1. Describe civil engineering

2. List types of projects civil engineers work on

3. Identify examples of civil engineering within their city

4. Construct structures using provided materials

After a short presentation about what $\mathrm{CE}$ is, the campers practiced structural engineering strategies in groups of three by building structures using spaghetti and marshmallows, shown in Figure 1. The goal of the activity was to build the tallest tower that maintained its shape over time. The height and sturdiness of the structures did appear to improve if the groups had older campers present, but all campers were able to complete and participate in the project. Next, the industry partner talked about her job and shared pictures and stories of different CE projects she had worked on around the city. The industry partner then walked the campers to a nearby pedestrian bridge construction site on campus where she was the project manager and told them about different de- sign considerations and problems they had to solve during construction.

Day 2: Industrial Engineering and Robotics. On the second day of camp, activities were designed to teach campers about industrial engineering and how robotics is used in advanced manufacturing. The industrial partners were a mechanical and an industrial engineer from an international automotive manufacturer that has a facility within the community. The learning objectives for the day were:

1. Describe industrial engineering and robotics

2. List types of projects industrial engineers work on

3. Interact with an artificial intelligence robot, virtual reality laboratory, and 3D printer

4. Construct coding sequence needed to navigate a robot through a provided course

At the beginning of the day, the industry partners shared stories about their engineering jobs and how their company uses robotics and 3D printing in the automotive industry. Campers, in groups of three, practiced developing coding sequences by guiding a robotic bee through different maps as shown in Figure 2. The girls had to visualize the course and required movements, and then program the necessary steps into the robots to navigate them successfully. Next, the faculty took the campers to three different campus laboratories: (1) Robotics, (2) Virtual Reality, and (3) 3D printing. 


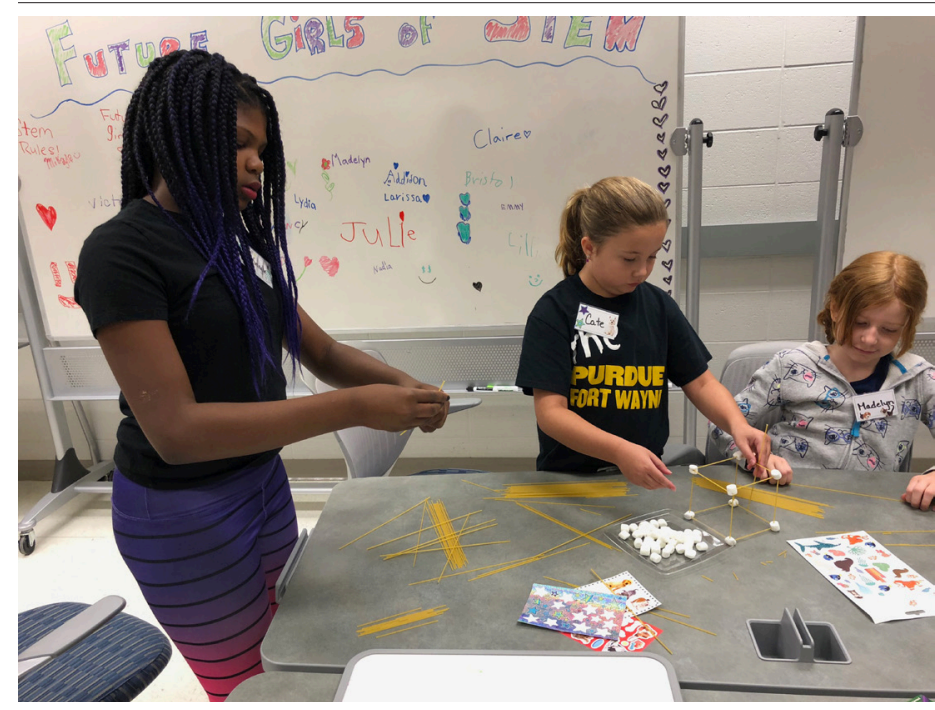

Figure 1. Photo of campers building structures from spaghetti and marshmallows.

In the Robotics Lab, campers interacted with a small robot who recognizes faces, remembers names, displays emotional responses, and plays soccer. In the Virtual Reality Lab, the girls played musical instruments and decorated rooms in a virtual environment. The 3D Printing lab had all the printers running different projects, and the campers got to see examples of past projects, what the inside of large prints look like, and how new designs are inputted into the printers. The faculty recognize that not all groups interested in starting their own STEM camp have access to laboratory facilities like this and suggest showing videos describing the technology as a cost-effective substitute.

Day 3: Environmental Engineering. The third day of camp was dedicated to environmental engineering and water resources. The industry partner for the day was a water resources engineer from the city water utilities office. The learning objectives for the day were:

\section{Describe environmental engineering}

2. List types of projects environmental engineers work on

3. Explore the city's drinking water source by visiting the nearby river

4. Test and compare the water quality of drinking water from the tap and untreated river water

To help the campers visualize their city's drinking water sources better, the environmental engineering day started with a trip to the riverfront that borders two sides of the university. This river is also the primary drinking water source for the city. While along the banks of the river, campers learned about the local water cycle and how our polluting decisions affect many people downstream. The industry partner discussed water contaminants and ways that

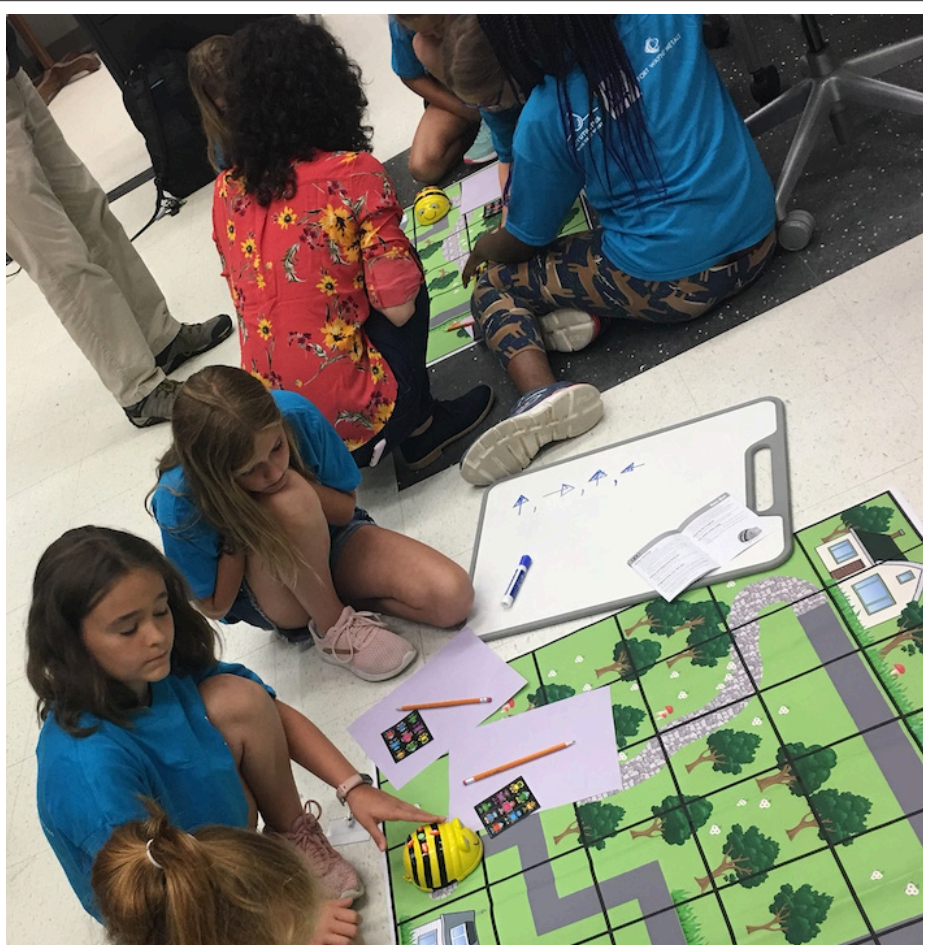

Figure 2. Photo of campers programming robotic bees to travel paths on large maps.

the girls could help protect the environment at home. Next, the campers visited an environmental engineering research lab and used water test strip kits to test and compare the water quality of tap water to untreated river water, shown in Figure 3. These kits are commercially available and are a cost-effective, interactive way to teach children about water quality. The day ended with a tour of a water biology lab where graduate students shared how they test river health by sampling local fish.

Day 4: Cybersecurity. The last day of camp focused on teaching campers about cybersecurity. Although cybersecu-

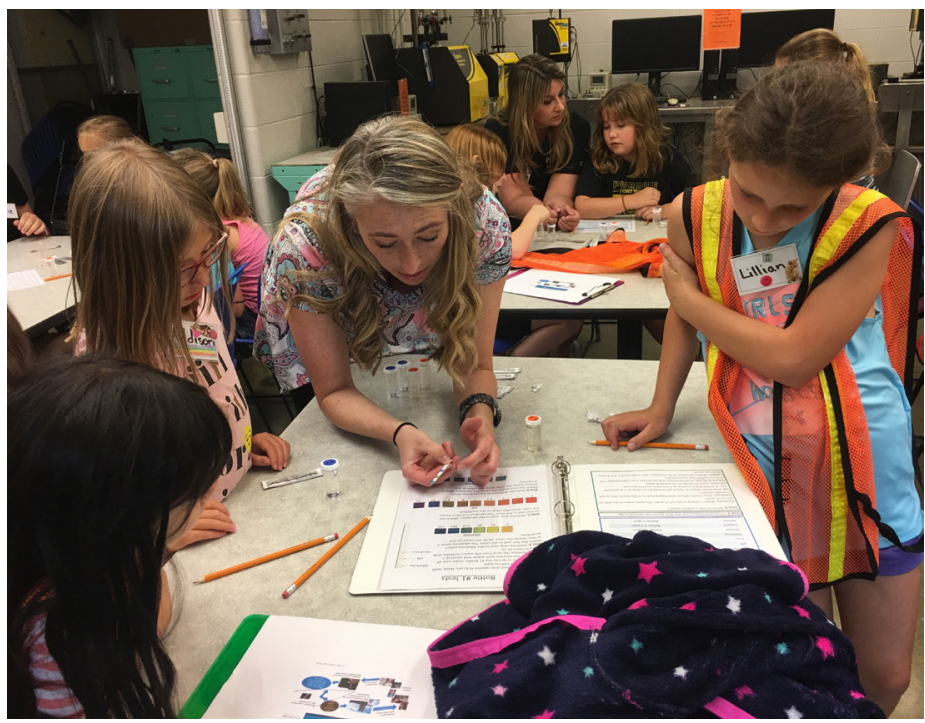

Figure 3. Photo of campers testing river and drinking fountain water quality. 
rity is not a specific type of engineering by itself, it is an important part of computer engineering and an important skill for young children to learn early and often. The industry partner was an information technology specialist from the university, and they shared stories with the girls about the different ways the university protects themselves online. The learning objectives for the day were:

1. Describe cybersecurity

2. Understand how to develop a strong password

3. Practice safety on social media networks

4. Identify examples of online bullying and determine safe ways to handle bullying

Because of the prevalence of online time and social media in the campers' lives, the cybersecurity day was focused on teaching the girls practical skills for maintaining safety online and how to work in groups. In the first activity, the girls tested the strength of various passwords and learned how to develop a password other people would not be able to easily guess. Next, the girls learned about effective teamwork skills and how to handle disagreements within groups, shown in Figure 4. The girls then evaluated different pretend social media accounts and learned how to identify suspicious information and malicious accounts. The day ended with the girls discussing what cyberbullying is, examples of cyberbullying, and different help resources available to them if they ever see or experience it.

Camp Implementation. The pilot four-day summer camp was conducted from June 24 to 27 in 2019. Twenty-one girls participated in the camp. A unique part of this camp was that it was an engineering camp for girls led entirely by female engineering mentors. As mentioned previously, the camp was planned and implemented by five female faculty. Additionally, there was a representative from the Girl Scouts, 1-2 female practicing engineers from industry, and 1-2 female undergraduate engineering students present each day of camp. Similar experiences are rare partially due to the lower number of female practicing engineers and faculty. Having the participants interact with, learn from, and form relationships with the women engineers were invaluable aspects of the camp. The female engineers and students shared real-life engineering knowledge and served as valuable mentors to participants. The goal was not only to teach the campers about engineering and engineering careers but also to show them through example that women can be successful engineers. In addition to serving as valuable mentors, undergraduate student volunteers gained valuable experience from educating the potential next generation of female engineering students. By the end of the week, camp participants earned three Girl Scout badges and part of a Journey badge

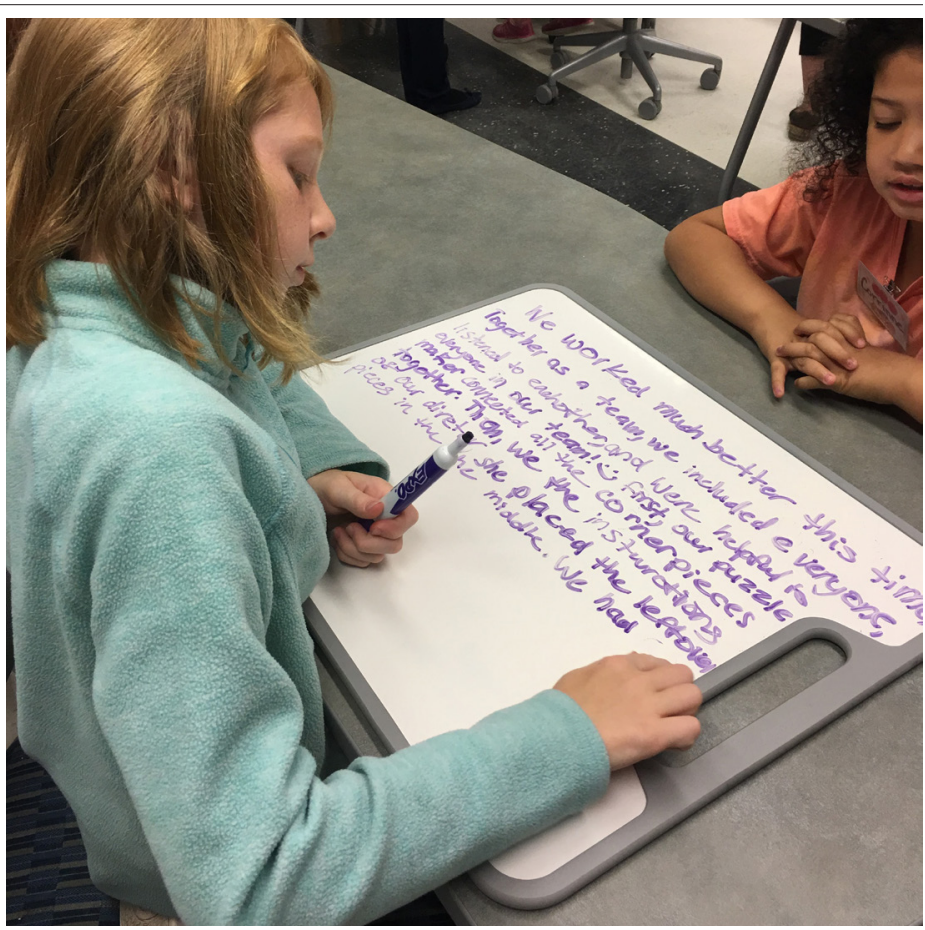

Figure 4. Photo of campers learning about how to be an effective team member.

including 1) Programming Robots; 2) Love Water portion of the WOW! Water Journey; 3) Cybersecurity Basics; and 4) Cybersecurity Safeguards. The faculty leaders also designed a special camp patch that was given out on the last day.

Assessment. To help leaders assess the camp, participants completed pre- and post-surveys. The surveys were distributed in paper form at the beginning and end of the camp, and 19 of the 21 campers completed both surveys. All campers consented to participate in the study about the camp, but two campers were not able to be physically present during the survey due to scheduling conflicts. No identifying data was collected on the surveys, so it is not possible to link participants' registration information to their survey responses. To accommodate for potential reading and comprehension levels of the campers, all questions were yes/no format, and a faculty member read each question out loud. A copy of the survey is included in the supplemental materials. Faculty instructed them to make their best guess on questions they were uncertain about. Questions on the survey primarily fell into six categories: (1) perceptions about or attitudes towards school, (2) external support system, (3) self-efficacy, (4) prior exposure to camp topics, (5) interest in camp topics, and (6) self-reported understanding of camp topics. Because of the target age group, the faculty did not feel it would be realistic to create knowledge-based questions to formally assess participants' understanding of the engineering topics covered during the camp. Instead, the survey asked participants to self-assess and report their perceived understanding. Although this is a subjective measure, the faculty felt it was more realistic for the girls' age. Lastly, the faculty felt 


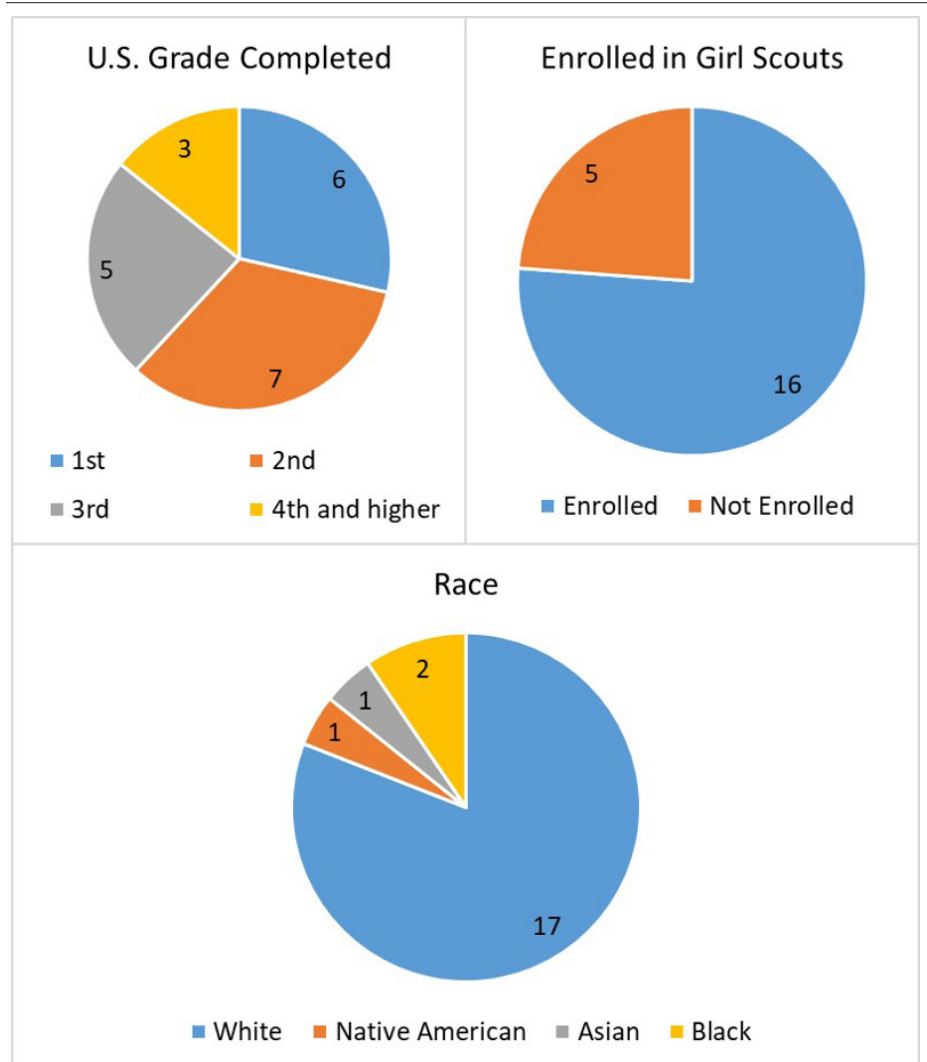

Figure 5. Camp participant demographics reported during registration. $(n=21)$

campers would be more likely to understand and have heard the term "robotics" before compared to "industrial engineering", so the faculty used the term "robotics" to describe the activities completed on the industrial engineering day of camp.

\section{RESULTS AND DISCUSSION}

The main goals of the Future Girls of STEM camp were to increase the participants' interest in, understanding of, and self-efficacy in engineering. To see the potential impact of the camp on the participants, the pre- and post-survey responses were compared and analyzed. Although the camp was marketed through the Girl Scout website for 2nd and 3 rd graders (8-10 years old), the group of campers was a wider age range and not all were registered Girl Scouts. A summary of camper grade-levels, ethnicity, and Girl Scout affiliation is shown in Figure 5. Since no identifiable information was collected on the surveys, this demographic data cannot be directly linked to the survey results. Six campers were below the originally intended age group (7 years old), 12 were within the original target age range, and three were older. Four of the campers were not associated with the Girl Scouts, but they had family that worked for the university. Because the campers were either members of Girl Scouts or associated with the university, the faculty dedicated a portion of the survey to determine whether each camper had participated in engineering-related activities before. Col-

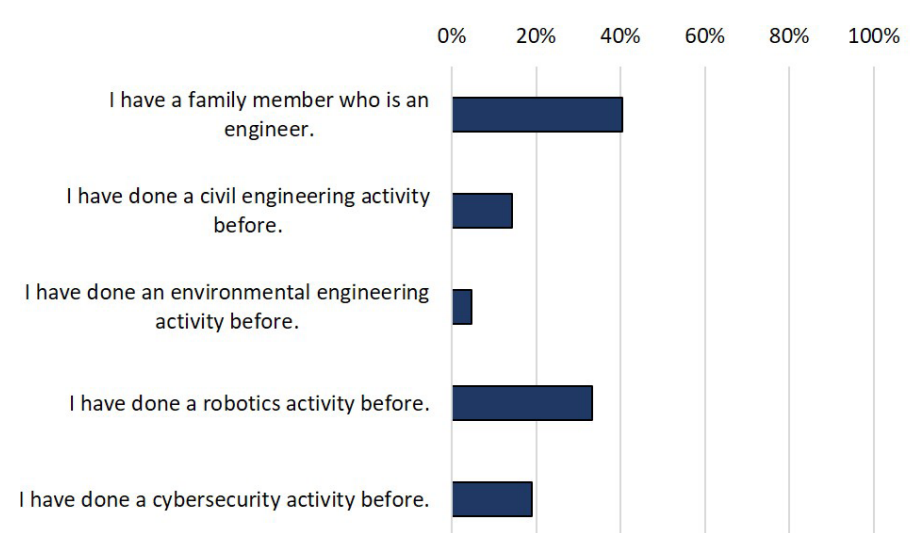

Figure 6. Exposure to engineering and camp topics on the pre-survey. $(n=19)$

lecting information about campers' previous participation in engineering activities was important to determine because campers already familiar with engineering might have different experiences than campers who are seeing all the material for the first time. Figure 6 shows the results of the survey questions about campers' prior exposure to engineering in general and the specific topics that were covered in the camp. Survey data about each camper's relationship with the university was not collected. This will be added to future surveys if enrollment allows participants to respond to the question while maintaining anonymity.

Few of the campers had participated in activities related to civil engineering, environmental engineering, or cybersecurity, but six campers did report participating in a robotics activity before attending the camp. Interactive robotics activities are often used at STEM events to teach kids about STEM because basic robotics kits are readily available online, so it makes sense that more students were exposed to this topic compared to the others. $40 \%$ of campers indicated that they had a family member who is an engineer. This high of a number is not surprising because people who are engineers are likely to encourage children in their lives to participate in engineering-related activities. However, it does indicate a potential for sampling bias within the group. From

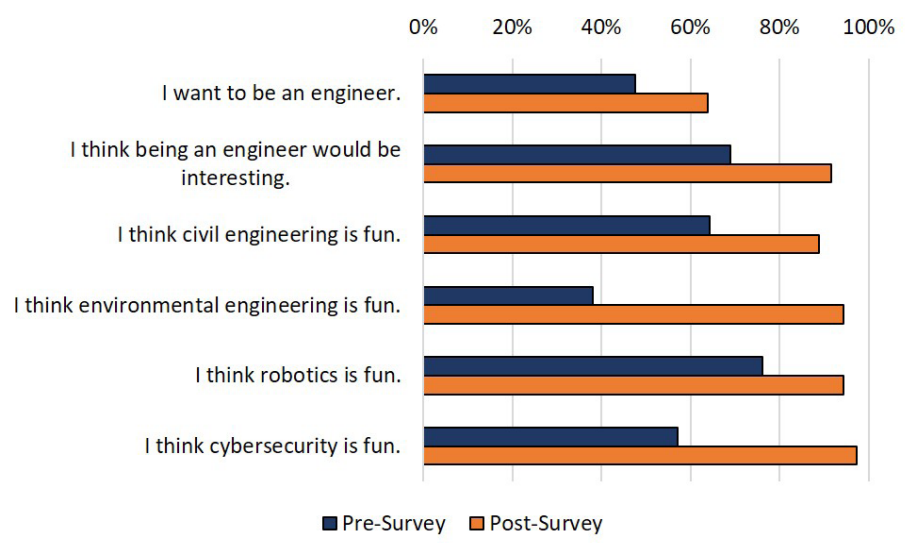

Figure 7. Camper interest in engineering topics on the pre- and post-surveys. $(n=19)$ 
these results, it seems that half the camp participants were familiar with engineering to some level, but few had any prior engagement with the types of engineering focused on in the camp.

By engaging the campers with hands-on activities, the faculty hoped to increase the girls' interest in engineering. It was assumed that most campers would already have a general interest in engineering purely because they signed up for the camp. Figure 7 shows the campers' responses about their interest in engineering and the specific topics covered in the camp.

Before participating in the camp activities, $69 \%$ of campers indicated that they believed being an engineer is interesting, and $48 \%$ responded that they wanted to be an engineer. The faculty were impressed with the level of interest in becoming an engineer before the camp had even started, and all camp volunteers saw the campers' enthusiasm throughout the week of the camp. In the post-camp survey, both questions saw an increase of 4 and 3 campers each, respectively. At the end of the camp, $92 \%$ of campers thought being an engineer would be interesting, and $64 \%$ wanted to be an engineer. Interest in the camp engineering topics all increased. The smallest increase was seen in robotics, but that is due to a high level of starting interest in the pre-survey. Before participating in the camp activities, $76 \%$ of campers already thought robotics was fun. The largest increase in interest was seen in environmental engineering. At the beginning of camp, only $38 \%$ of campers thought that environmental engineering was fun compared to $94 \%$ at the end of the camp. This high increase was most likely partially due to participants being initially unfamiliar with environmental engineering. Only one camper had participated in an environmental engineering activity before the camp.

Although the faculty questioned whether it would be possible to assess true learning gains through a traditional test due to participants' ages, the campers were asked to report their perceived understanding of the topics covered at the camp. The results of these questions are shown in Figure 8.

Before completing the camp activities, $38 \%$ of campers felt comfortable listing the types of jobs an engineer does, $76 \%$ felt comfortable describing what it means to be a good leader, and $43 \%$ believed they could describe robotics and cybersecurity. No campers felt comfortable describing civil or environmental engineering. After the camp, all campers felt comfortable describing the topics covered in camp or chose to not respond to the question. Additionally, the percent of campers who felt comfortable listing the types of engineering jobs increased to $83 \%$.

To measure their self-efficacy, campers were asked about their believed ability in math, science, and engineering. There was no significant change in responses between the pre- and post-survey. However, most campers had an overall high belief in their school abilities with $94 \%$ of campers

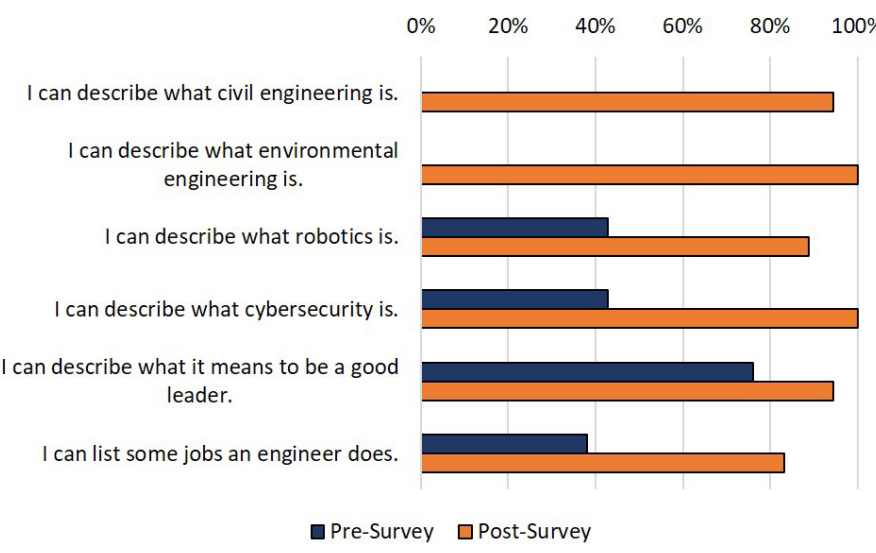

Figure 8. Self-reported understanding of engineering and topics covered in camp. $(n=19)$

reporting that they believed they were good at science and good students in general. The faculty were glad to see that $78 \%$ of campers believed they could be an engineer.

To help determine what effects the camp had on campers versus other outside factors, the campers were asked to self-report how they thought the camp impacted them on the post-camp survey. $94 \%$ of participants reported learning at camp that an engineering job could be interesting, 100\% learned about engineering jobs they did not know about before, and $78 \%$ said they were thinking about becoming an engineer more after completing the camp than before.

The Future Girls of STEM summer camp was a successful step towards increasing girls' understanding of and interest in engineering. The four-day camp introduced 21 campers to different types of engineering by completing hands-on activities led by a team of women from different engineering fields. Although there was no change in self-efficacy seen on survey responses, participants had overall high levels of self-efficacy about their abilities in school, math, science, and engineering. Campers reported increased interest in and understanding of engineering and the topics discussed within the camp.

One of the factors that made the camp possible was the high number of engaged volunteers that were present throughout the planning process and camp activities. Even though the campers were engaged and enjoyable to work with, it was beneficial to have a maximum camper to adult ratio of 3 to 1 plus one adult focused on leading the room through the various activities. Having this ratio gave the campers personalized attention, made sure that nobody was overwhelmed, and allowed adults to help participants who needed supplemental aid to complete activities. Recruiting enough engaged adults to serve as mentors throughout the camp and provide a ratio of 3:1 is highly recommended.

Although there were no major issues encountered during the camp, the faculty plan on limiting future camps to campers who are 8 years old or older. The youngest campers struggled with focusing on activities and exhibited some ma- 
turity issues that were not seen in older campers. The faculty do believe it is possible and beneficial to hold STEM camps for younger girls but believe younger girls would thrive in a camp developed specifically for their age group and that the FGS activities described previously are best for slightly older campers.

Future Research and Next Steps. The faculty intend to continue to hold the Future Girls of STEM camp each summer. To continue the pipeline, future camps will be expanded to include older demographics. Campers between 8 and 10 years old will still be primarily recruited, but the target demographic will be expanded to also include 11 and 12-yearold girls. This allows girls who participated in past camps to continue attending and not age out. This will most likely require additional volunteers to help lead activities for the different ages and will require new activities to be developed each year so that campers are not doing the same activities multiple years in a row. The faculty are more than willing to continuously develop new activities to engage return campers each year.

It was originally planned to hold another FGS summer camp in a similar format to the pilot year during the summer of 2020. However, because of the COVID-19 pandemic, the faculty converted the 2020 FGS camp to an at-home and online format. The goal of the new format was to deliver an educational, interactive experience to participants without putting a substantial burden on parents and guardians. This involved creating a detailed, engaging curriculum with hands-on activities to teach campers about biomedical, water, and mechanical engineering. Pivoting the 2020 Future Girls of STEM camp to a virtual format was critical to keep the momentum going and to continue the relationships with campers, many of whom returned for the second year. The logistics and results of the at-home and online experience will be the topic of future research papers.

\section{ASSOCIATED CONTENT}

Supplemental material mentioned in this manuscript can be found uploaded to the same webpage as this manuscript.

\section{AUTHOR INFORMATION Corresponding Author}

Rebecca R. Essig. 2101 E. Coliseum Boulevard, Fort Wayne, Indiana 46805. essigr@pfw.edu

\section{Author Contributions}

The manuscript was written through contributions of all authors. All authors have given approval to the final version of the manuscript.

\section{ACKNOWLEDGMENTS}

The authors would like to thank Purdue University Fort Wayne for supporting the Future Girls of STEM summer camp and the Girl Scouts of Northern Indiana Michiana for their invaluable partnership.

\section{FUNDING SOURCE}

This project was funded by Purdue University Fort Wayne and conducted under IRB Procotol \#1904022038.

\section{ABBREVIATIONS}

CE: Civil Engineering; FGS: Future Girls of STEM; GS: Girl Scouts (of the United States of America: STEM: Science, Technology, Engineering, and Mathematics

\section{REFERENCES}

Anderson, L.S. and Gilbride, K.A. (2003). Pre-university outreach: Encouraging students to consider engineering careers. Global Journal of Engineering Education, 7, 87-94.

Backer P. and Halualani, R. (2012). Impact of self-efficacy on interest and choice in engineering study and careers for undergraduate women engineering students. Paper presented at 2012 ASEE Annual Conference and Exposition, San Antonio, Texas. https://peer.asee.org/21475 American Society for Engineering Education Annual Conference and Exposition.

Blandino, J., and Hardin, J-M., (2015). Assessing the impact of engineering outreach frequency on middle-school students' interest in engineering. Proceeding of the 2015 ASEE Annual Conference and Exposition, Seattle, WA. June 14-17.

Cech, E., Rubineau, B., Silbey, S., and Seron, C. (2011). Professional role confidence and gendered persistence in engineering. American Sociological Review, 76(5), 641-666.

Choney, S. (2018). Why do girls lose interest in STEM? New research has some answers - and what we can do about it. Microsoft Features. Retrieved from: https://news.microsoft.com/features/why-do-girls-lose-interest-in-stem-newresearch-has-some-answers-and-what-we-can-do-aboutit/

Deckard, C., and Quarfoot, D. (2014). Analysis of a short-term STEM intervention targeting middle school girls and their parents (Research-to-practice). Proceedings of the 2014 ASEE Annual Conference and Exposition, Indianapolis, IN, June 15-18.

Girl Scout STEM Pledge - Girl Scouts. (2017, November 6). Retrieved on July 21, 2020 from https://www.girlscouts.org/ en/adults/donate/STEM-pledge/STEMpledge.html 
Gooden, F., Borrego, M., Edmister, W., Waller, T., and Watford, B. (2010). An assessment of long-term impacts of three on-campus K-12 enrichment programs. Proceedings of the 2010 ASEE Annual Conference and Exposition, Louisville, KY, June 20-23.23.

Gossage, L. (2011). A four-year study of a female engineering outreach program-The influence of math ability on female students career decisions for engineering. Women in Engineering Proactive Network.

Hubelbank, J., Demetry, C., Nicholson, S.E., Blaisdell, S., Quinn, P., Rosenthal, E., and Sontgerath, S. (2007) Long-term effects of a middle school engineering outreach program for girls: A controlled study. Proceedings of the 2007 ASEE Annual Conference and Exposition, Honolulu, HI, June 24-27.

Krathwohl, D. R. (2002). A revision of Bloom's taxonomy: An overview. Theory into Practice, 41(4), 212-218.

McCormick, J.R., Talbert-Hatch, T., and Felhaus, C. (2014). Increasing female participation in engineering: Evaluating *CAMP NAME* summer camp. Proceedings of the 2014 ASEE Annual Conference and Exposition, Indianapolis, IN, June 15-18.

Microsoft.com (n.d.) https://www.microsoft.com/en-us/ corporateresponsibility/skills-employability/girls-stem-computerscience, retrieved on April 30, 2020.

Noel-Levitz, Inc. (2007). "National Freshman Attitudes Report." Iowa City, IA.14.

Roberts, K. and Hughes, R (2019). Girls' STEM identity growth in co-educational and single-sex STEM summer camps. Journal of STEM Outreach. https://doi.org/10.15695/ jstem/v2il.07

Roy, J. 2018. "Engineering by the Numbers.” American Society of Engineering Education.

Sandrin, S., Borror, C.M. (2013). Student perceptions and interest in engineering: Effects of gender, race/ethnicity, and grade level. Proceedings of the 2014 ASEE Annual Conference and Exposition, Atlanta, GA, June 23-26.13.

Yoder, B. L. 2015 "Engineering by the Numbers.” American Society of Engineering Education. 